\title{
Research \\ Incorporating Science into the Environmental Policy Process: a Case Study from Washington State
}

\author{
$\underline{\text { Tessa B. Francis }}^{1}, \underline{\text { Kara A. Whittaker }}^{1}, \underline{\text { Vivek Shandas }}^{1}, \underline{\text { April V. Mills }}^{1}$, and Jessica K. Graybill ${ }^{1}$
}

\begin{abstract}
The incorporation of science into environmental policy is a key concern at many levels of decision making. Various institutions have sought to standardize the protection of natural resources by requiring that decisions be made based on the "best available science." Here we present empirical data describing the incorporation of best available science in the land-use policy process on a local scale. Results are based on interviews with planners and others who conducted scientific reviews associated with a Washington State Growth Management Act amendment that requires the inclusion of best available science in protecting critical areas. Our results show that jurisdictions varied with respect to how they included science in their land-use policies. Specifically, we found that smaller jurisdictions were very reliant on scientific information provided by state agencies, communicated frequently with other jurisdictions and agencies, and most often let scientific information guide the policy development process. Medium-sized jurisdictions, in contrast, were more inwardly focused, relied predominantly on local information, communicated little with outsiders, and more often looked to political influences to guide the policy process. Large jurisdictions, including most counties, often generated their own best science, communicated with and often informed state agencies and other jurisdictions, and more often considered science first during the policy development process. Jurisdictions also differed in terms of how best available science was defined, and how jurisdictions dealt with conflicting scientific information. Our results provide empirical evidence of the variation with which best available science is used in environmental policies.
\end{abstract}

Key Words: best available science; critical areas ordinance; environmental policy; Growth Management Act; land-use planning; Washington State

\section{INTRODUCTION}

The use of science in environmental policy is a primary goal of resource management and conservation that is relevant to issues at global, national, and local scales. Explicit calls for the inclusion of science in policy decisions are found at levels ranging from the United Nations to city governments. The relationship between science and policy has been the topic of special issues of scientific journals, e.g., a 1995 supplement to BioScience, issue 51(6) of BioScience in 2001, an Ecological Society of America symposium in 1999, and countless national and international meetings involving scientists, policy makers, and natural resource managers. The debate about the use of science in policy has recently been highlighted by a report charging the White House with distorting the process by which scientific information is used to develop policy (UCS 2004). However, there is little empirical information about how science is actually used in formulating environmental policy at any scale.

The debate about the relationship between science and policy centers on questions related to how scientific information is incorporated into public policy. It is largely believed that there are inherent differences between the fundamental structures and traditions of science and policy. Correctly or not, the scientific process is assumed to be objective and logical compared with the policy process, which is often described as nonlinear and chaotic (Norse and Tschirley 2000). Alternate views describe the 
scientific method as limiting and inflexible, and inappropriate for use in environmental policy (Tarlock 2002). Ultimately, gaps between science and policy probably exist because of their different stated values and goals (Collingridge and Reeve 1986, Policansky 1998, Kinzig and Starrett 2003).

Communication of science represents one of several key barriers to the use of science in policy (Policansky 1998, Weber and Word 2001, Kinzig and Starrett 2003), for example, when scientific arguments are used to mask a debate over values (Policansky 1998, Kinzig and Starrett 2003). Scientific uncertainty itself may also pose a major barrier to the effective use of science in policy (Lubchenco 1995), in part as a result of the difficulties in quantifying uncertainty (Kinzig and Starrett 2003). Furthermore, ecological research has traditionally excluded humans, which may have contributed to the gaps between science and public policy, especially in urban areas (Alberti et al. 2003).

Over the past decade, environmental policies have been amended to require that decisions be based on "best science" or "best available science" (BAS). These terms are often invoked to indicate the existence of some standard against which the scientific information collected and used by policy makers will be judged. In addition, requiring that decisions be based on BAS ensures that a record exists of the decision-making process that can be challenged and defended later. This requirement is applied to policies at all levels of decision making, including the United Nations Environmental Programme (UN 1992), the U.S. strategic policy on global climate change (CCSP 2003), the U.S. Endangered Species Act (ESA), the Washington State Salmon Recovery Program (JNRC 1999), and Washington State's Growth Management Act (36 R.C.W. $§$ 70A.172). The BAS standard is controversial, as evidenced by legal action (Bogert 1994) as well as a report by the U.S. General Accounting Office (GAO) on the effectiveness of the BAS tenet of the U.S. Fish and Wildlife Service (USFWS) in the ESA (Brennan et al. 2003, GAO 2003). The GAO expressed concerns over the adequacy and function of the data used by the USFWS to designate critical habitat, suggesting that there were some disconnects between the science and its application in the ESA. The meaning of BAS is ambiguous, and its principle is often invoked without accompanying definitions or prescriptions for use (Bisbal 2002). Despite the widespread requirement that environmental policies be based on BAS, to date there have been few empirical studies on how decision makers include science in policy (but see Eliasson 2000).

Washington State's Growth Management Act (GMA) requires cities and counties to include BAS as part of the planning process for protecting critical areas. Critical areas include wetlands, fish and wildlife habitat conservation areas, aquifer recharge areas, geologically hazardous areas, and frequently flooded areas (Ousley 2003). The GMA requires that critical areas be protected before other planning requirements are fulfilled while acknowledging that other considerations are part of the decision-making process about land use. A technical work team assembled to interpret the GMA concluded that, by requiring the inclusion of science in critical areas ordinances, the state aims to "protect the functions and values" of critical areas (Ousley 2003). In addition, they acknowledged that some development may occur within designated critical areas, and that not all critical areas must be protected to the same degree (Ousley 2003). The work team also recognized that, before jurisdictions can include BAS, they must accomplish two tasks: (1) they must identify and collect the BAS relevant to their critical areas, and (2) they must interpret the assembled information to determine its validity and applicability to their local characteristics.

Washington State's Department of Community Trade and Economic Development (DCTED) has provided some guidance to jurisdictions in accomplishing these tasks (Ousley 2003), but has left much of the decision-making process up to local discretion. For example, the DCTED developed definitions of BAS, including the types of scientific information and associated characteristics that are considered by the state to be the BAS (Ousely 2003). Despite such efforts by state government, and because local governments must balance the protection of critical areas with other GMA goals such as increasing housing density within the urban growth boundary, it is likely that the various methods by which jurisdictions collect, interpret, and incorporate BAS mediate the influence of scientific information on the development of policy related to critical areas and, ultimately, their protection. Attention to jurisdictional characteristics such as population size, degree of urbanization, or resource base, as opposed to policies aimed at blanket solutions such as requiring the BAS, may be more effective in achieving policy goals. 
In this study, we aim to provide some of the first empirical data addressing the major outstanding questions related to how science informs policy decision making. For example, how do policy makers determine what is the "best" available science? What gaps, if any, actually exist between science and policy? To answer these questions, we interviewed local policy makers in western Washington about how they used BAS to update critical areas ordinance (CAO), i.e., the local policy that governs land-use decisions in critical areas. Specifically, we present results related to how planners and others define, collect, and interpret BAS. Our study addresses four key questions: (1) How do jurisdictions define BAS? (2) How extensive was the review of BAS? (3) What were the major steps in the process for updating the CAO, and at what stage was scientific information incorporated? (4) How do jurisdictions make policy when they encounter what they perceive as conflict within BAS?

Where policy makers are required by law to incorporate science into policy, it is extremely useful to describe this process, not only for the purposes of adapting science to meet the needs of policy, but also for informing the interactions between policy makers and researchers. The results of our study provide much-needed information to ecologists who aim their research toward informing environmental management decisions. Our general goal here is to provide a case study lending insight into the process by which scientific information is incorporated into land-use planning policy at local scales, the resolution that is particularly relevant to issues of urbanization in the United States and across the globe.

\section{METHODS}

\section{Critical areas ordinance update process}

Washington State's Growth Management Act (GMA) was updated in 1995 to require cities and counties, as part of the planning process, to include best available science (BAS) in designating and protecting the functions and values of critical areas. In addition, jurisdictions must "give special consideration to conservation or protection measures necessary to preserve or enhance anadromous fisheries" (Ousley 2003). Typically, jurisdictions designate and protect their critical areas in a policy document called a critical areas ordinance (CAO). In 2002, the GMA was further amended to require jurisdictions to update their CAOs every $7 \mathrm{yr}$, and the first jurisdictions were due to complete their updates by December 2004. Thus, our study was motivated in part by the fact that most western Washington jurisdictions would be incorporating BAS into their CAOs for the first time in 2004. It is the duty of the jurisdiction to justify its decisions about designating and protecting critical areas through its review of BAS. CAOs are subject to a public hearings process, and objections to the designation and protection of critical areas may be filed with the Western Washington State Growth Management Hearings Board, which then rules on the appropriateness of the ordinance.

\section{Study sample and design}

Our study area included the nine counties in Washington State mandated to update their CAOs by this first deadline (Fig. 1). We studied the cities and counties that had completed at least half of the BAS review associated with the update as of early 2003; their status was determined by phoning each jurisdiction. We contacted the planning or other departments responsible for the ordinance update of all 112 cities and nine counties in the study area. Our study sample included 21 cities and six counties, or $23 \%$ of all possible jurisdictions updating their CAOs by 2004. In addition, we focused exclusively on the sections of each jurisdiction's CAO that dealt with the biological critical areas: wetlands and fish and wildlife habitat, which also typically incorporated the "special consideration" for anadromous fisheries.

Following standard qualitative research methods, we used an interview strategy for data collection. Our approach involved an exploratory phase during which we conducted preliminary interviews, followed by the use of a semistructured interview protocol (Miles and Huberman 1994). In the preliminary interviews conducted over the phone, jurisdictions were queried about their general impressions of the requirement to include BAS in their CAOs. We used the information gathered during the preliminary interviews to develop the semistructured interview protocol (Miles and Huberman 1994). We pretested the protocol on planners in jurisdictions outside of our sample and 
Fig. 1. Map of counties of Washington State. Counties and cities therein required to update their critical areas ordinance by December 2004 are shaded. (Adapted from http://quickfacts.census.gov/qfd/maps/washington map.html).

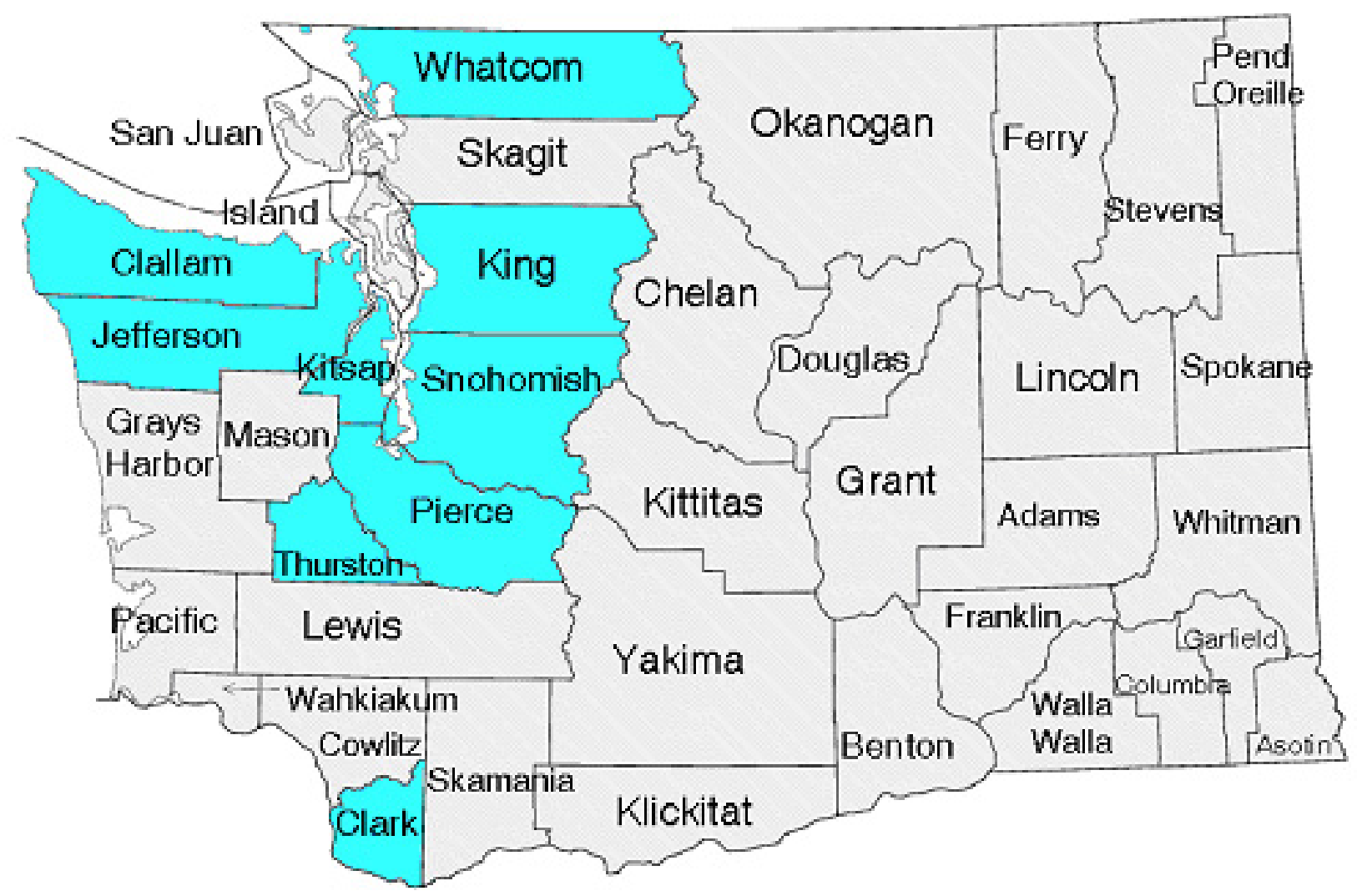

on other local government employees involved in the implementation of the GMA amendment.

From December to May of 2003 we conducted 43 structured interviews, representing 27 jurisdictions, with city and county planners in lead positions for the CAO update process in their jurisdictions, as well as with any consultants they had hired to conduct the BAS review. In those cases in which the responsibility for the BAS review was specific to a particular type of critical area, we selected interviewees who had focused specifically on wetlands and fish and wildlife habitat conservation areas, because of the concern over threatened salmonid species and habitat in this region. We conducted face-to-face interviews with the majority of our respondents $(n=40)$, but, for logistical reasons, three were interviewed by telephone. The interviews consisted of a mixture of open-ended, fixed-response, i.e., yes/no, and scale questions, with the majority being open-ended. Interviewers were closely familiar with the interview guide and occasionally used prompts to clarify the intent of the question or to elicit a more detailed response. The interviews lasted 60-90 $\mathrm{min}$ and were taped and later transcribed. The four major themes that are the focus of this study are as follows:

How did the jurisdiction define BAS, and what types 
of scientific information did they consider to be BAS? What was the extent (breadth, scope) of the review of BAS by the jurisdiction? Where did it get its scientific information? What were the major steps taken by the jurisdiction in the process of updating its CAO? How did the jurisdiction make decisions when there was contradictory scientific information? The complete interview guide is found in Appendix 1.

\section{Data analysis}

We developed an approach for analyzing interview data according to the principles of content analysis (Glaser 1967, Strauss and Corbin 1990), which describes an iterative process of breaking down, conceptualizing, and restructuring textual data. We imported entire interview transcripts into Atlas.ti (Scientific Software Development, Berlin, 1997), a qualitative data analysis software package for organizing and coding interview data. Codes, or descriptive labels, were applied to selections of text from the interviews to organize responses into categories for analysis. These codes were developed using both a priori (Miles and Huberman 1994) and inductive coding techniques (Strauss and Corbin 1990), such that some categories of responses were developed in advance based on our preliminary research, and some were developed based on what was said by the interviewees. The coding process is iterative and flexible, ultimately allowing for the designation of codes to be responsive to the data. To minimize bias in our results, coding was performed by all the authors, and each author coded a unique portion of the transcript. Throughout the data analysis process, all the authors compared coding strategies for consistency.

We hypothesized that we would see some variation in the use of BAS in CAOs, and that one pattern of this variation would be along a gradient of jurisdictional population size. We used population size as a proxy for variables that might impact the use of science in policy, such as resource base, level of urban development, and distance to a metropolitan center. We therefore analyzed differences in the patterns of BAS use between jurisdictions of different population sizes. We grouped jurisdictions into size categories based on U.S. Census 2000 figures: small $=1-30,000(n=11$ jurisdictions $)$, medium $=30,001-100,000(n=8$ jurisdictions), and large $=>100,000 \quad(n=7$ jurisdictions, including all five counties in the sample). It is worth noting that $67 \%$ of the large jurisdictions were counties, which may differ from cities in terms of their political structure, financial resources, staff resources, and other key characteristics that may influence the questions addressed in this research. However, for most of the results shown here, the responses from the two large cities did not vary consistently from those of the four counties. It is also important to note that, because not all individuals answered every question, sample size varies slightly throughout the results.

\section{RESULTS}

\section{Definition of best available science}

Jurisdictions of different population sizes varied with respect to the types of scientific information defined as best available science (BAS) and used in their critical areas ordinance (CAO). All the jurisdictions interviewed used a variety of types of scientific information in their BAS review process (Fig. 2). Of 25 jurisdictions, 17 considered peerreviewed literature to be BAS. In addition, 15 of 25 jurisdictions deemed government agency publications, such as those produced by the Washington State Department of Fish and Wildlife, to be BAS. These two categories were the most commonly used types of scientific information by jurisdictions of all sizes (Fig. 2). Jurisdictions differed, however, when it came to classifying data that were not peer reviewed as BAS. Some small (10\%) and medium-sized $(25 \%)$ jurisdictions used information that was not peer reviewed, such as local monitoring or survey data, as a form of BAS, in contrast with large jurisdictions, which did not.

Consultants hired by jurisdictions used peerreviewed literature more frequently than planners did in their science review process. Consequently, whether or not a jurisdiction hired a consultant influenced the type of scientific information it used in its CAO (Fig. 2). Additionally, jurisdictions that hired consultants relied on a broader range of types of BAS (Fig. 2A). Of 11 small jurisdictions in our sample, six hired consultants, and those that did were approximately twice as likely to use state agency literature as were small jurisdictions that did not hire consultants. Medium-sized jurisdictions that did not use consultants were much less likely to use peer-reviewed literature than were 
Fig. 2. Types of scientific information considered best available science (BAS) by jurisdictions in Washington State. Of $n=25$ jurisdictions, 15 hired consultants to review BAS (A), and 10 did not (B). Results for the large category include one city and three counties that hired consultants and two counties that did not. Because most jurisdictions consider more than one type of information to be BAS, total proportions shown for each population size category are greater than 1.0. Government agency publications include syntheses of peer-reviewed literature as well as internal research documents and reports that often are internally reviewed. Expert opinion includes the verbal opinions of jurisdiction biologists, agency biologists, consultants, and other individuals who were deemed to be "experts" on a given subject. Information that was not peer reviewed includes monitoring data, inventories, jurisdictional research, and other sources of data that have not gone through a peer-review process.

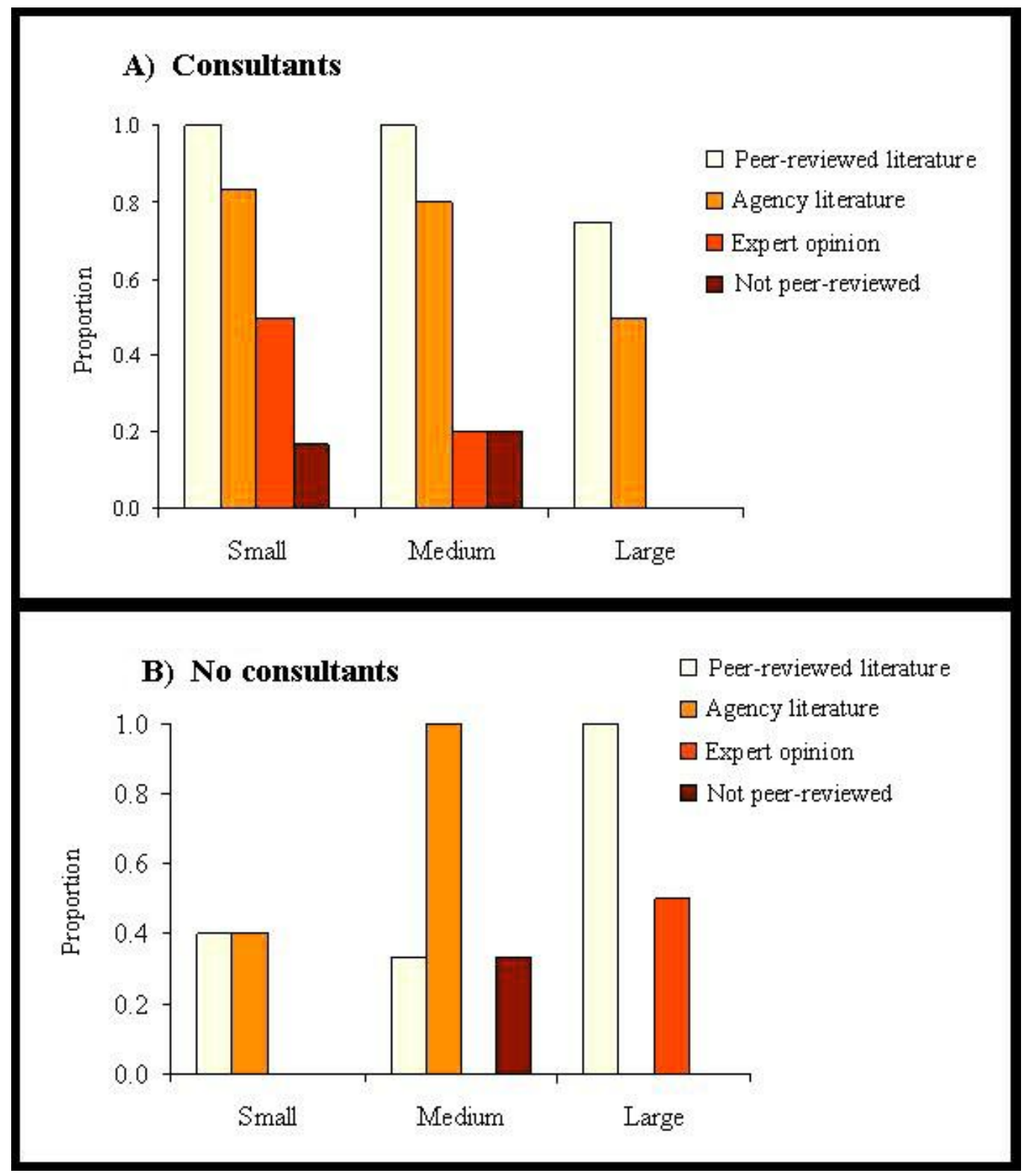


Table 1. Extent of the review of best available science (BAS) by jurisdictions of different population sizes. Numbers represent the percentage of jurisdictions that followed one of four strategies for collecting scientific information used to update their critical areas ordinance $(n=25)$.

\begin{tabular}{|c|c|c|c|c|c|}
\hline Population size & $\begin{array}{l}\text { Used an existing } \\
\text { bibliography (\%) }\end{array}$ & $\begin{array}{l}\text { Conducted ongoing } \\
\text { BAS review (\%) }\end{array}$ & $\begin{array}{l}\text { Generated own } \\
\text { BAS }(\%)\end{array}$ & $\begin{array}{l}\text { Extensive inventory } \\
\text { of critical areas }(\%)\end{array}$ & $\begin{array}{l}\text { Solicited comments } \\
\text { from others }(\%)\end{array}$ \\
\hline $\begin{array}{l}\text { Small } \\
(n=11)\end{array}$ & 91 & 9 & 0 & 0 & 82 \\
\hline $\begin{array}{l}\text { Medium } \\
(n=8)\end{array}$ & 38 & 25 & 0 & 50 & 38 \\
\hline $\begin{array}{l}\text { Large } \\
(n=6)\end{array}$ & 0 & 50 & 50 & 33 & 83 \\
\hline
\end{tabular}

jurisdictions of the same size with consultants $(33 \%$ vs. 100\%). Large jurisdictions that hired consultants, including both cities in the category, frequently $(50 \%)$ used agency literature and rarely $(0 \%)$ relied on expert opinion (Fig. 2A). Large jurisdictions without consultants, in contrast, rarely $(0 \%)$ used agency literature, but often $(50 \%)$ relied on expert opinion (Fig. 2B).

\section{Extent of best available science review}

Our results show that different-sized jurisdictions varied in the extent to which they collected scientific information (Table 1). Small jurisdictions most often stated that they used an existing bibliography as a starting point for their literature review. These bibliographies were either compiled by another jurisdiction or by the Washington State Department of Community, Trade and Economic Development, the department responsible for assisting jurisdictions with their update process. For example, one respondent stated, "... I think in this particular case the state was pretty involved in trying to identify those sources that were appropriate ... we didn't attempt to produce any of our own scientific info, with not having the resources to do that. So it wasn't really a question in most cases, because the state department was responsible to kind of identify what they considered to be BAS. So it didn't require a lot of analysis on our part."

Small jurisdictions did not conduct extensive inventories and did not have in place a program for regular, ongoing review of BAS. In contrast, medium-sized jurisdictions more often stated that they had extensive inventories of their critical areas and were conducting ongoing reviews of BAS. Large jurisdictions, which in this case comprise five counties and one city, did not use bibliographies from other sources, frequently had a BAS review process in place, and had some on-the-ground information about their critical areas (Table 1).

Small jurisdictions commonly (82\%) solicited comments on their BAS reviews, draft ordinances, or other components of the update process from other jurisdictions, state agencies, or other stakeholders in the process (Table 1). Large jurisdictions also regularly $(83 \%)$ communicated with others outside of their jurisdictions about the CAO update process. Medium-sized jurisdictions were the least likely (38\%) to solicit comment from others about their CAOs.

\section{Steps in the critical areas ordinance update process}

We found that jurisdictions varied with respect to how BAS was incorporated into the policy-making process. We developed a conceptual model for the CAO update process to describe two typical starting points subsequent to the requirement by Washington State that jurisdictions update their ordinances: BAS Review and Policy Directive. Policy Directive is the expression of the political goals of the jurisdiction, usually by city or county council (Fig. 3). In $45 \%$ of all jurisdictions, BAS 
Fig. 3. A generalized model of the critical areas ordinance update process. Point A represents one starting point, specifically, review of science; $45 \%$ of all jurisdictions review science as the first step in updating their ordinance. Point B represents an alternate starting point at which political considerations precede scientific information and often drive research; $23 \%$ of all jurisdictions consider politics before science in updating their ordinance. In gap analysis, a jurisdiction's ordinance is compared to scientific findings or the state's model ordinance to identify missing pieces. Policy directive is potentially applied by two stakeholders in the process: the City or County Council and the Planning Department, Planning Commission, or work groups that include political appointees and citizens.

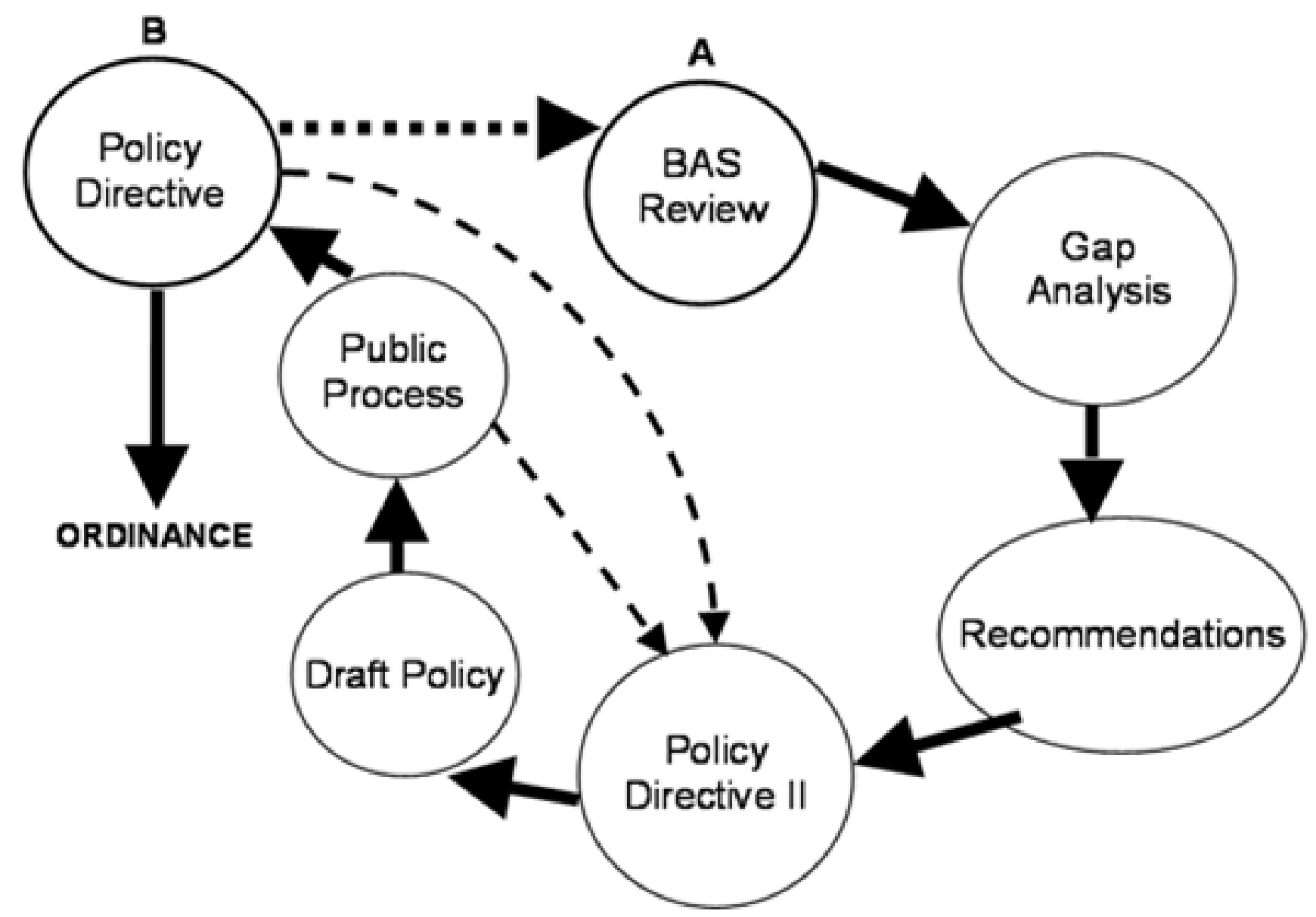

Review is the first step in the policy formation process (Point A in Fig. 3). Typically, this is followed by a gap analysis in which the jurisdiction's existing ordinance is compared against scientific findings or the state's model ordinance and "gaps" or areas that require updating to bring the ordinance in line with scientific recommendations or the state's guidelines are identified. Following the gap analysis, recommendations for updates to the ordinance are drafted, typically by the person(s) who reviewed the science. These recommendations are given to the staff responsible for writing the ordinance, usually the jurisdiction's planning department, for inclusion in the revised ordinance. At this point (Policy Directive II), the planning department may consider the political climate of the jurisdiction or the political aims of the city or county council, which may in some cases result in a policy 
that diverges somewhat from the purely scientific recommendations. A draft policy is then produced and taken through a public review process, which is often iterative and results in more ordinance revisions. Once the public review process is complete, the draft is forwarded to either the city or county council for adoption. The council may request further revisions, after which the policy may be sent through the public process again.

In nearly a quarter of jurisdictions examined, the policy formation process is initiated by the political directive of either the city or county council (Fig. 3 ). In these situations, policy directives drive the scientific review, either by directing the review of BAS toward certain findings to achieve a desired outcome, or by limiting the scope of the scientific review to certain sections of the ordinance update. As one interviewee noted, " ... [the city/county] council decided to ... write their own [critical areas ordinance] ... they figured this was their best shot at making their mark on a policy document. It actually says that in the contract - they want their policy direction to be incorporated. Now they would've had their shot at it anyway, once it got to them-it's a lot better if you can have your fingers in it from the very beginning and draft it and direct it all the way from the beginning to the very end."

From here, the process follows the review process described above, although the scientific review is typically abbreviated and less emphasis is placed on the gap analysis.

Two additional policy formation frameworks exist. In one, the model ordinance created by the state government is adopted largely without changes, including the biophysical standards for critical area protection, and no scientific review or policy directive is applied. This process is used by $14 \%$ of the jurisdictions. The last framework is one in which scientific information and political concerns are addressed simultaneously and throughout the policy formation process. In this framework, representing $18 \%$ of the jurisdictions, the basic steps are the same, but at each point the scientific information is considered in conjunction with the socio-political landscape of the jurisdiction. For example, in one jurisdiction, scientific information included in the state's model critical area code is considered alongside existing city code and planning commission recommendations. As one interview respondent explained, " ... what the consultant and the city staff have come up with is this matrix as a tool ... [The matrix describes] each different critical area and what the BAS ought to be, based on state statute requirements and ... the [state's] model code and GMA. [It summarizes] what the [state's] model code is saying, what our existing city code says, and then what the planning commission has been developing as recommendations to the city council."

Jurisdictions of different population sizes varied as to when BAS was incorporated into the policy process (Table 2). Approximately three-quarters of large jurisdictions, including both cities in this category, started by reviewing BAS at the beginning of their ordinance update process. Likewise, the number of small jurisdictions that considered science first was greater than the number that either started with a policy direction, or considered both policy and science concurrently. In contrast, none of the medium-sized jurisdictions stated that they began the policy update process by considering only scientific information. Further, in approximately two-thirds of these jurisdictions, policy directive drove the rest of the process. Approximately onequarter of small jurisdictions relied on the state's model ordinance without using either the direction of science or policy to inform the update process.

\section{Resolving decisions about conflicting best available science}

We found some variation in how jurisdictions make choices about conflicting scientific information. Because most cities and counties incorporate critical areas designations and protection measures into land use regulations, they typically include specific biophysical standards of protection, for example, wetland buffer widths. Therefore, jurisdictions often select single values even when they perceive that there is disagreement within the scientific community about appropriate protections. A majority of respondents $(64 \%)$ said that they decide on these single values by evaluating the scientific information, whereas $31 \%$ considered political or legal influences. One example of how jurisdictions evaluated science was that they use the most reliable or rigorous science available, as described by another respondent, "So what we do is try to look at all of [the studies] and figure out which is most applicable and which is most reliable - which has been developed under the more controlled circumstances so that you can actually relate it, hopefully, to the situation that you're concerned 
Table 2. Critical areas ordinance update process followed by jurisdictions in western Washington State. Numbers represent the percent of jurisdictions following one of four policy formation processes $(n=25)$. The first three processes are diagrammed in Fig. 2.

\begin{tabular}{lllll}
\hline \hline Population size & $\begin{array}{l}\text { Consider best } \\
\text { available science } \\
\text { first (\%) }\end{array}$ & $\begin{array}{l}\text { Consider political } \\
\text { influences first } \\
(\%)\end{array}$ & $\begin{array}{l}\text { Science and } \\
\text { policy are } \\
\text { considered con- } \\
\text { currently (\%) }\end{array}$ & $\begin{array}{l}\text { Used state's } \\
\text { model ordinance } \\
\text { only (\%) }\end{array}$ \\
\hline $\begin{array}{l}\text { Small } \\
(n=11)\end{array}$ & 36 & 18 & 18 & 28 \\
$\begin{array}{l}\text { Medium } \\
(n=3)\end{array}$ & 0 & 67 & 33 & 0 \\
$\begin{array}{l}\text { Large } \\
(n=7)\end{array}$ & 72 & 14 & 14 & 0 \\
\hline
\end{tabular}

with."

This pattern did not hold, however, for jurisdictions of all population sizes (Fig. 4). After evaluating science, the most common strategies for small jurisdictions were relying on state government sources $(40 \%)$ and considering political or legal influences (50\%). One respondent noted, "Scientists have the luxury of looking only at the science, whereas a city, a functioning multifaceted entity, a political entity has to think about and balance a wide range of considerations when applying the science."

Similarly, the second most common (38\%) influence on choices for medium jurisdictions was politics or legality. Another respondent described this as, "Policy pull. You look at what you're trying to do. When you have conflicting information like that you always have to look at what the goals of the city are. You have to look at where the council wants us to go in the future. We weigh towards policy."

In addition, medium-sized jurisdictions often (25\%) said they applied a conservative or precautionary approach in the face of conflicting scientific information. A respondent from a medium jurisdiction stated, "I have a fairly conservative approach towards protecting resources where I think that in the absence of information, we should err on the side of protecting things. So that's probably the overarching philosophy that guides my decision making."

In contrast, the second most common (43\%) strategy used by those reviewing science in large jurisdictions, both cities and counties, was to provide a range of scientific criteria to decision makers, rather than making a single recommendation.

\section{DISCUSSION}

Environmental policies at all levels of government are increasingly expected to be developed through decision-making processes with a scientific basis. One of the goals of Washington State's Growth Management Act in requiring that policy makers use best available science (BAS) is to provide more specific policy direction to cities and counties that ensures protection of critical areas (Copsey 1999). However, the results of this study suggest that the use of scientific information by local governments in land-use policy is variable, and that requiring BAS may not serve the function intended for all jurisdictions. 
Fig. 4. Strategies used by jurisdictions of different sizes to choose between conflicting scientific information ( $n=11$ small, 7 medium, and 7 large jurisdictions).

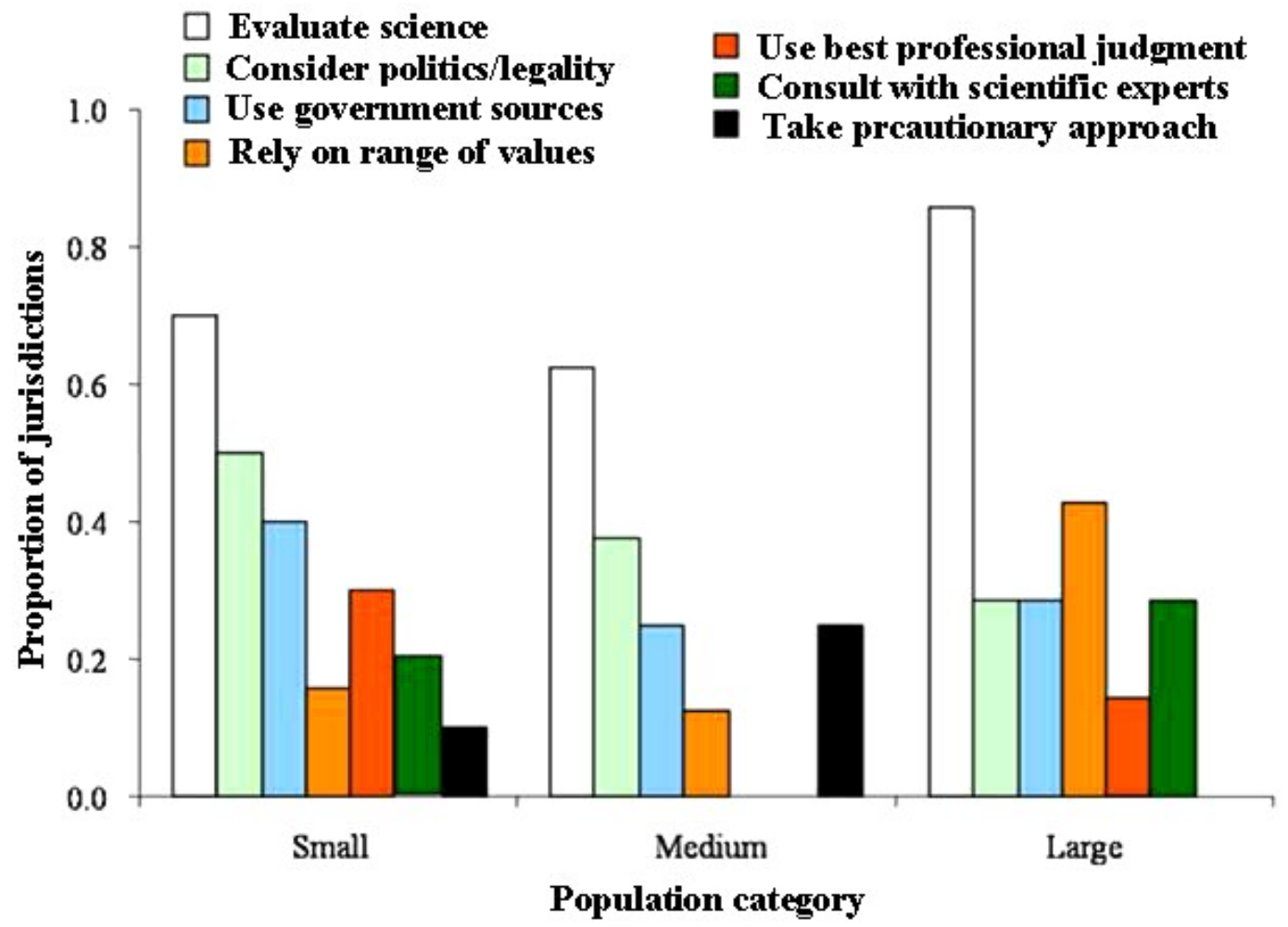

\section{Size matters}

We found that the size of a jurisdiction's population was important in determining how science was collected and used in developing their critical areas ordinance (CAO). Small jurisdictions with populations of less than 30,000 conducted less direct analysis of scientific information (Table 1). This could be because smaller jurisdictions may have more limited financial resources because of their small tax base; in addition, they may not have biologists on staff. No small jurisdiction interviewed had scientific experts on staff, as compared with $13 \%$ of medium jurisdictions and $71 \%$ of large jurisdictions. Small jurisdictions were more heavily reliant on outside resources in developing their ordinances, with little internal generation or analysis of BAS and little specific information about the distribution of critical areas on their landscape. This was evidenced by their preferential use of BAS bibliographies produced by state agencies or other jurisdictions (Table 1) as well as by the relatively high use of agency literature and communication with other jurisdictions and agencies (Figs. 2 and 4). This suggests that the choice of science used by small jurisdictions is at least in part influenced by their limited financial resources and related lack of scientific expertise in planning departments. One potential result of this is that state agencies may have more direct influence over critical areas protection policies in smaller jurisdictions, because the most commonly used BAS bibliography was the one prepared by the responsible state agency. The state of Washington 
was at least in part aware of the potential for this financial disadvantage, because they offered small grants (U.S. \$16,000) to all jurisdictions to help defray the cost of the ordinance update process.

The patterns of collection and use of BAS by medium-sized jurisdictions demonstrates that these jurisdictions have greater resources as well as a higher degree of on-the-ground knowledge about their critical areas. Higher levels of financial resources, as would be expected because of the larger tax base, as well as larger staffs with more biologists allowed for ongoing review and collection of scientific information as well as extensive inventories (Table 1). Extensive inventories, which usually include detailed mapping and classification of all the critical areas in a jurisdiction, are a source of information about local conditions and are often costly and timeconsuming to produce. The Growth Management Act (GMA) requires jurisdictions to designate their critical areas, and medium-sized jurisdictions are consistently able to do this.

The relatively high level of internal biogeographical knowledge in medium-sized jurisdictions that did not hire consultants was coupled with some reclusive tendencies, such as relatively low reliance on expert opinion as BAS (Fig. 2), little communication with other jurisdictions or agencies regarding their BAS reviews (Table 1), and low levels of expert consultation or government agency input to help resolve conflicts (Fig. 4). This infrequent consultation with agencies or other experts implies a more inward focus, with an emphasis on local conditions and locally generated information. In addition, some medium-sized jurisdictions were highly insular, indicating no use of peer-reviewed literature or government agency data but, rather, high dependence on locally generated information. As one respondent noted, "I intend to show people we're using local knowledge, local resources, local science, local common sense, and we are not flying in from Harvard with a 1500page manual on how wetlands should be."

This locally focused approach by medium-sized jurisdictions was coupled with a greater influence of politics on the ordinance update process. After evaluating science, the most common influences on the choices made by medium-sized jurisdictions about conflicting scientific information were politics or legal issues $(43 \%)$ and the use of a conservative or precautionary approach (29\%; Fig.
4). Policy direction from city or county councils and stakeholders is not uncommon at this stage of the process, and, in the face of scientific uncertainty, a conservative approach is often the safest one, both legally and ecologically. Critical areas ordinances are subject to challenge by any party, and such disputes are resolved by the Growth Management Hearings Board (GMHB). If a jurisdiction's CAO is challenged and found to be out of compliance with the GMA by the GMHB, the jurisdiction may risk the loss of state funding.

Small jurisdictions were also influenced by politics, but this influence probably had less effect on the overall update process. Although nearly half $(45 \%)$ of small jurisdictions also considered political influences when making choices about conflicting science, only $9 \%$ used this as their sole strategy when making choices. This is in contrast to mediumsized jurisdictions, $29 \%$ of which relied on political or legal considerations as their sole strategy in making decisions about conflicting science. Political influence ultimately is reflected in the policy update process. Medium-sized jurisdictions most frequently started their ordinance update process with policy directives or other political influences, rather than science. Thus our results suggest that medium-sized jurisdictions have enough resources to make them less reliant on outside sources, more inwardly focused, and more responsive to local political influences than to agency science.

Large jurisdictions, which included all the counties in our sample, have the greatest resource base, both financially and in terms of staff expertise. The patterns we observed in large jurisdictions are consistent with what might be expected of counties, given their elevated resource levels. However, we also found that the two cities in the large category shared these characteristics, suggesting that the patterns we see are not necessarily associated with a particular jurisdictional level, but rather with population size and resource base.

Not only did larger jurisdictions more often regularly review scientific information outside of the ordinance update process, but they also frequently conducted their own scientific research and generated their own BAS, which was often peerreviewed and published (Table 1). The overwhelming majority of the BAS used by large jurisdictions is peer-reviewed literature, suggesting that large jurisdictions are familiar with the 
literature, probably because of their greater resources and expertise. Moreover, large jurisdictions, when faced with making choices about conflicting scientific information, evaluated the science itself and relied less on documents produced by government agencies. In several cases, the flow of information between large jurisdictions and agencies was reversed: counties and large cities often provided data and research findings to agencies. Thus, the larger jurisdictions generate their own BAS, are more familiar with the primary literature, and also provide BAS to government agencies.

The level of political influence in the ordinance update process was relatively low in large jurisdictions. These jurisdictions were less frequently guided by the political climate in their jurisdictions when confronted with conflicting results in BAS (Fig. 4), and instead preferentially relied on ranges of biophysical standards. In these cases, respondents frequently dealt with conflicting scientific information by giving a range of scientific values, also called scenarios (Bennett et al. 2003), to decision makers. This is a strategy common to consultants charged with scientific review, indicating their role in providing scientific information but refraining from making choices for the jurisdictions. As one consultant observed, "What we usually tell our clients and the cities and counties is that the science doesn't give you a one point, one answer. It gives you a range."

Additionally, the policy update process in large jurisdictions was most frequently informed by science, rather than by political direction (Fig. 3). It may be, therefore, that the high resource levels and high degree of connection to peer-reviewed literature in large jurisdictions supercede reliance on political motivations for decisions about critical area protection.

\section{Role of consultants}

Consultants were commonly hired by the jurisdictions in our sample (62\% of all jurisdictions hired consultants) to review BAS, make recommendations about protection standards, update ordinance language to meet state requirements, and, in some cases, write entire sections of the CAO. Another factor that influenced both the collection and use of scientific information was the involvement of consultants in the scientific review process, and this influence differed among jurisdictions of different sizes. Over half of the small jurisdictions in our sample hired consultants, many of them using grants from Washington State's Department of Community Trade and Economic Development (DCTED) to pay for consultant services. For these small jurisdictions, consultants increased the effective availability of scientific information for jurisdictions that might otherwise have been limited by their expertise and resources. Also, hiring consultants to review BAS more often was associated with using science to inform the rest of the update process in jurisdictions of all sizes. In some cases in which science was not the driver of the policy update process, and in which jurisdiction staff were responsible for the entire update process, jurisdictions simply adopted the model ordinance without any science review. Thus, it appears that one role of consultants in this process is to temper the isolation characteristic of small jurisdictions and broaden their access to science.

What is uniformly clear in these results is the influence of the Washington State government on the CAO update process. Jurisdictions of all sizes, whether they hired consultants or not, relied heavily on the resources provided by DCTED. Nearly all jurisdictions had seen or used both the model ordinance and the Citations of Recommended Sources of Best Available Science prepared and circulated by DCTED when it was known as the Office of Community Development (OCD 2002). Because of this, there was a high degree of similarity among the bibliographies of all the jurisdictions included in this study, although we do not present the results of those analyses here. In addition, the appearance of a specific piece of scientific literature in a jurisdiction's bibliography was not necessarily associated with following the protection levels contained therein. State agencies often review draft CAOs for compliance with the GMA prior to adoption by the jurisdiction. This process provides an opportunity for BAS to carry more weight, but lower standards are allowed if they are explicitly justified by the jurisdiction in the context of the other goals of the GMA. Thus, despite an overarching similarity in the definition of BAS, the nature of the BAS used in critical areas ordinances by the jurisdictions in our sample varies widely. 


\section{CONCLUSION}

Complex environmental policy decisions are often informed by scientific data, and calls for the inclusion of best available science (BAS) in environmental policies occur at local to global scales. As yet, scientists and policy makers have not determined how best to make this relationship work. It is expected that governments, which are required to represent all their constituents and their myriad needs, will consider many factors in decisions about resource use and protection. However, even in situations in which it has been determined that the protection of critical habitat should be the primary goal of the decision-making process, it is likely that this protection will vary.

Our results show that the incorporation of scientific information into local policies is not uniform, and that, in many cases, political rather than scientific forces have a greater influence on decisions about natural resources. This study reflects the common perception among those individuals responsible for protecting critical areas in western Washington State that they are straddling a science/policy divide. It is unclear to whom the responsibility belongs for this continued science/policy disconnect. Scientists often present conflicting information to policy makers without providing adequate tools for handling scientific uncertainty and disagreement. Further, there is room within the findings presented by scientists for policy makers to mask their political or social values with scientific data, confirming what others have suggested: that the different values and objectives inherent in science and policy prevent successful partnerships. It is also clear that financial resources and other pressures on local governments can influence the protection of natural resources, and that policy makers in different jurisdictions are not using the same science when making their decisions.

To fully understand the direct connection between the use of science and on-the-ground protection of natural resources, quantitative analyses of the variability in protection measures as a function of the policy process are necessary. As the world becomes more and more urban (Sadik 1999), the gap between scientific information, typically collected in "natural" settings, and the policy goals of growing cities may widen. The good news is that heavy involvement by state agencies, in this case in the form of suggested protection measures based on the review of scientific literature, can bridge the gap of limited financial and expertise resources. However, it is likely that, given the often divergent goals and values of scientists and policy makers, and until the pressing environmental questions are posed jointly, simply offering up the goods, i.e., BAS, and telling people to use them correctly will not work to uniformly protect natural resources.

Responses to this article can be read online at:

http://www.ecologyandsociety.org/vollo/iss 1/art35/responses/

\section{Acknowledgments:}

The authors would like to thank Gordon Bradley, John Marzluff, Clare Ryan, and Daniel Schindler for their input and suggestions in improving this manuscript. An anonymous reviewer also provided helpful suggestions. We would also like to thank the above group as well as Marina Alberti and Craig ZumBrunnen for their guidance during the development of this project. This research was funded by the National Science Foundation (IGERT-0114351) and the University of Washington's College of Forest Resources, particularly its Rachel Wood's Endowed Graduate Program.

\section{LITERATURE CITED}

Alberti, M., J. M. Marzluff, E. Shulenberger, G. Bradley, C. Ryan, and C. Zumbrunnen. 2003. Integrating humans into ecology: opportunities and challenges for studying urban ecosystems. BioScience 53:1169-1179.

Bennett, E. M., S. R. Carpenter, G. D. Peterson, G. S. Cumming, M. Zurek, and P. Pingali. 2003. Why global scenarios need ecology. Frontiers in Ecology and the Environment 1:322-329.

Bisbal, G. A. 2002. The best available science for the management of anadromous salmonids in the Columbia River Basin. Canadian Journal of Fisheries and Aquatic Sciences 59:1952-1959.

Bogert, L. M. 1994. That's my story and I'm stickin' to it: is the "best available" science any available science under the Endangered Species Act? Idaho Law Review 31:85-150. 
Brennan, M. J., D. E. Roth, M. D. Feldman, and A. R. Greene. 2003. Square pegs and round holes: application of the "best scientific data available" standard in the Endangered Species Act. Tulane Environmental Law Journal 16:387-444.

Climate Change Science Program (CCSP). 2003. The U.S. Climate Change Science Program: vision for the program and highlights of the scientific strategic plan. CCSP, Washington, D.C., USA.

Collingridge, D., and C. Reeve. 1986. Science speaks to power: the role of experts in policymaking. St. Martin's Press, New York, New York, USA.

Copsey, A. D. 1999. Including best available science in the designation and protection of critical areas under the Growth Management Act. Seattle University Law Review 23:97-143.

Eliasson, I. 2000. The use of climate knowledge in urban planning. Landscape and Urban Planning 48:31-44.

General Accounting Office (GAO). 2003. Endangered species: Fish and Wildlife Service uses best available science to make listing decisions, but additional guidance needed for critical habitat designations. U.S. General Accounting Office, Washington, D.C., USA.

Glaser, B. G., and A. L. Strauss. 1967. The discovery of grounded theory: strategies for qualitative research. Aldine, Chicago, Illinois, USA.

Joint Natural Resources Cabinet (JNRC). 1999. Statewide strategy to recover salmon. JNRC, Olympia, Washington, USA.

Kinzig, A., and D. Starrett. 2003. Coping with uncertainty: a call for a new science-policy forum. Ambio 32:330-335.

Lubchenco, J. 1995. The role of science in formulating a biodiversity strategy. BioScience (Supplement):S7-S9.

Miles, M. B., and A. M. Huberman. 1994. Qualitative data analysis: an expanded sourcebook. Second edition. Sage Publications, London, UK.

Norse, D., and J. B. Tschirley. 2000. Links between science and policy making. Agriculture Ecosystems and Environment 82:15-26.

Office of Community Development (OCD). 2002. Citations of recommended sources of best available science for designating and protecting critical areas. OCD, Olympia, Washington, USA.

Ousley, N. K. 2003. Critical areas assistance handbook: protecting critical areas within the framework of the Washington Growth Management Act. Washington State Department of Community, Trade and Economic Development, Olympia, Washington, USA.

Policansky, D. 1998. Science and decision making for water resources. Ecological Applications 8:610-618.

Sadik, N. 1999. The state of world population 1999 -6 billion: a time for choices. United Nations Population Fund, New York, New York, USA.

Strauss, A., and J. Corbin. 1990. Basics of qualitative research. Sage Publications, London UK.

Tarlock, A. D. 2002. Who owns science? Pennsylvania State Law Review 10:135-154.

Union of Concerned Scientists (UCS). 2004. Scientific integrity in policymaking: an investigation into the Bush administration's misuse of science. UCS, Cambridge, Massachusetts, USA.

United Nations (UN). 1992. Agenda 21, Chapter 35: Science for sustainable development. United Nations Department of Economic and Social Affairs, Division for Sustainable Development, Rio de Janeiro, Brazil.

Weber, J. R., and C. S. Word. 2001. The communication process as evaluative context: what do nonscientists hear when scientists speak? BioScience 51:487-495. 


\section{APPENDIX 1. INTERVIEW TRANSCRIPT}

The following is the full interview conducted with planners in western Washington State, as well as the consultants they hired, concerning the update of critical areas ordinances (CAOs) in their jurisdictions. The interviews were conducted primarily face-to-face, and the questions are a mix of three types: open-ended, fixed response, i.e., yes/no, and scale questions. The interviews were taped and later transcribed, and the text was used in the analyses presented in the main article. We do not present results from all of the data collected below in the present article.

\section{Introduction spoken to interviewee prior to beginning interview}

We are interested in the science-policy relationship, and our goal is to understand how the critical areas ordinance update process varies across jurisdictions and what factors can explain this variation. Specifically, we are focusing on wetlands, fish and wildlife habitat conservation areas, and anadromous fish.

\section{Questions to planners:}

1. Within your department, please explain the main steps in the update process, and identify the main people involved and their roles. What other groups are part of the update process, and how are they related to your department and each other? What stage in the update is your jurisdiction currently in? Questions to consultants:

Please explain what you were specifically hired to do for the city or county's CAO update. How extensive of a review were you tasked with? How far into this process are you?

\section{Questions to all:}

Has your jurisdiction completed a critical areas inventory? How detailed is it? Has your current CAO changed since the last CAO? In a general sense, how much has it changed? More specifically, what types of changes occurred? Do you expect that this update process will lead to additional variances or exemptions in your new ordinance? Considering all the changes you've just described, what are the main factors you think are responsible for these changes? Are any of the changes being made to the current CAO a direct result of your best available science review? If yes, which ones? Please describe why. If no, please describe why not. (If update not fully completed) Do you anticipate that the final draft of your CAO will be different from your current draft? On a scale of 1 to 5, how much do you expect it to change?

\begin{tabular}{llllll}
\hline \hline 1 & 2 & 3 & 4 & 5 & $?$ \\
\hline no change & minor change & moderate change & significant change & $\begin{array}{l}\text { very significant } \\
\text { change }\end{array}$ & $\begin{array}{l}\text { don't know (too } \\
\text { early) }\end{array}$ \\
\hline
\end{tabular}

In addition to your critical areas ordinance, does your jurisdiction have other measures or regulations to protect or conserve specific critical area types? What is your working definition of best available science (BAS)? What types of scientific information constitute BAS? How did you compile your BAS list? For example, did you start with an existing list? Are you familiar with the BAS list prepared by the state Office of Community Development? Does your bibliography vary from it? How? Why? What qualities or characteristics of BAS make it useful to you? When there is conflict in BAS, how do you decide what BAS to include in making recommendations for the CAO? What types of information do you pull from BAS? Using an example, could you describe how you synthesize multiple ideas, numbers, or information found in BAS? If BAS suggests a range of biophysical criteria to protect a critical area type, how do you decide what criteria to recommend for the CAO? How well does BAS apply to the critical areas in your jurisdiction? 
Can you describe why/why not, using an example? Are there any constraints on your review of BAS? (Only for those who have completed their update process) Did your BAS review lead to any specific biophysical changes?

(If YES) Was one of those changes in your buffer widths?

(If YES) Can you identify any specific BAS that led to the buffer width change?

If the BAS didn't lead to that change, how did you arrive at the specific change?

(If NO) Why not?

Were there any other specific changes to the biophysical criteria?

We're interested in three main types of critical areas. I'd like to know which of them this jurisdiction has. Wetlands? Fish and Wildlife Habitat Conservation Areas? Anadromous Fish? I'm going to read you a direct quote from the RCW (36.70A.172) related to critical areas ordinances and then ask you to interpret three parts of it. "In designating and protecting critical areas under this chapter, counties and cities shall include the best available science in developing policies and development regulations to protect the functions and values of critical areas." For each critical area type you just listed, how do you interpret "designating and protecting?" For these same critical areas, how do you interpret "functions and values?" How do you interpret "shall include the best available science?" Are you working with scientific experts on this update? (If yes) What kind? On a scale of 1 to 5 , what is the priority of the update process for your jurisdiction?

\begin{tabular}{lllll}
\hline \hline 1 & 2 & 3 & 4 & 5 \\
\hline no priority & minimum priority & moderate priority & high priority & very high priority \\
\hline
\end{tabular}

Is there a specific person or group who is making the update a priority? (If yes) Who and why? Does this priority impact the way the science is reviewed or how the ordinance is updated? (If yes) How? What proportion of your time is devoted to the update process? Are there any competing environmental regulatory issues you are dealing with? 